\title{
SOCIAL AND EPIDEMIOLOGICAL RATES RESEARCH IN OLDER AGE POPULATION OF UKRAINE
}

\author{
Alla Kotvitska, Oleksandra Pastukhova \\ Department of Social Pharmacy, The National University of Pharmacy, Kharkiv, Ukraine
}

\begin{abstract}
A comparative analysis of the morbidity statistics and disease prevalence among the working and older age Ukrainian population is given in the article. The data on the general health level of elderly and senile people in 2008-2012 is presented. It was determined that morbidity of all diseases in the working age population in the period of 2008-2012 exceeds the corresponding rates among the older age population.The evolution of all diseases' prevalence in the working age population has undulating nature. In older age population a negative trend of increasing prevalence was observed. According to the analysis, a positive trend towards gradual reduction of morbidity in the older age population in general and by its basic structure classes was determined, except for eye diseases and its appendage. Compared to 2008, morbidity rates of the eye and its appendage increased by $0.46 \%$. All diseases' prevalence in elderly population of the period of 2008-2011, had a steady upward trend, only in 2012 there was a slight decrease. Basic trends of the health improvement of the Ukrainian population for this age contingent are defined in the article.
\end{abstract}

Keywords: Ukraine, morbidity, prevalence, elderly population

\section{INTRODUCTION}

Public health is a reflection of the social and historical development of society, the vitality of people living in a particular area for several generations. The priority of any country is to preserve and promote the health of its population through high-quality and affordable health care with a focus on disease prevention, reduction of disease prevalence and increase in life expectancy (1). A drawback of health care in Ukraine, its constant underfunding, reflects on the life quality and accessibility of medical and

Address for correspondence: Oleksandra Andriivna Pastukhova, Department of Social Pharmacy, The National University of Pharmacy Blucher 4, 61168 Kharkiv, Ukraine e-mail:oleksandra_pastukhova@ukr.net

Received: April 1, 2015

Accepted: May 11, 2015 pharmaceutical care for the population, but to the greatest extent it affects the poor, especially in elderly and senile age. Taking into account the demographic changes which take place in almost all countries, the rapid growth of elderly and senile patients' number in the world, the study of medical and demographic characteristics, health status and trends of this contingent of the population, is important in terms of making the forecast for the further development of health.

The purpose of the study is to conduct a comparative analysis of morbidity, disease prevalence in the working age and older age population, and the defined structures of the noted indicators for the main classes of diseases among the older age population.

\section{MATERIAL AND METHODS}

The methodological background of the research was the data of the Medical Statistics Centre of the Ukrainian Ministry of Healthcare, presented 
in the annual reports of the public health state for the period of 2008-2012.

During the study we used the retrospective method, in which we used the statistics for morbidity in different years. Statistical data were processed, grouped and compared. We used a graphical analysis method to achieve this.

\section{RESULTS AND DISCUSSION}

In recent years demographic changes take place all over the world that indicate a sharp increase in the number of elderly and senile people. Ukraine is a country with a high level of aging population. This process is a natural, historical, and, unfortunately, irreversible phenomenon.

There is a steady trend of increase in the number of elderly and senile people. Thus, in 1991 the share of working age population in Ukraine was $18.6 \%$, in $2012-21.2 \%$ with a predicted trend for further increase of this demographic performance. According to the World Health Organization (WHO) by 2050 the proportion of people over 60 years will increase, up to $38.1 \%$, particularly, the part of people over 80 years could become 3.5 times bigger in accordance with the increasing life expectancy.

This trend is also characterized by a gradual increase in the proportion of the patients with complex chronic disorders, reduced mobility and a high degree of dependence on public support among the population of Ukraine.

Taking into account this data, the first stage of our study was to conduct a comparative analysis of

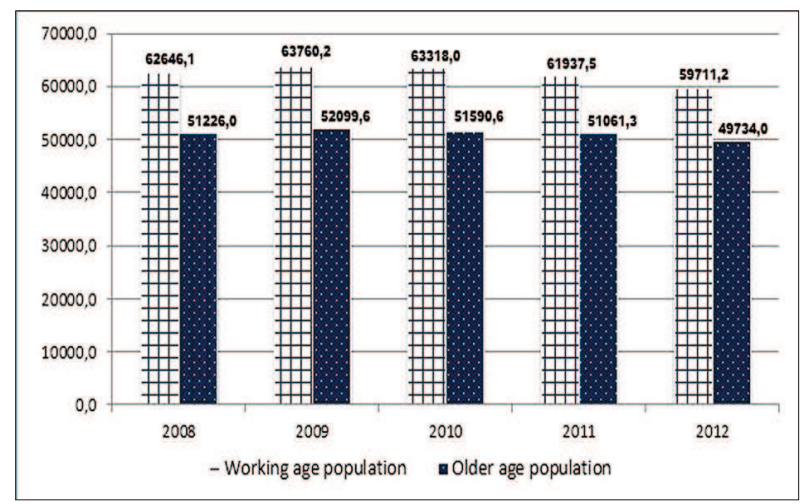

Fig. 1. Morbidity dynamics of all diseases in the working and older age population in 2008-2012 (per 100 thousand of population) statistics and prevalence of disease in the working and in older age population in Ukraine.

According to the analysis, morbidity of all diseases in the working age population in the period of 2008-2012 exceeds the corresponding rates among the older age population. In the structure of morbidity among the working age population there is an increasing proportion of endogenous pathology due to the large prevalence of risk factors. There is an increasing share of socially important and dangerous diseases. This is particularly true of the incidence of tumors, endocrine diseases, metabolic diseases and others. However, it should be noted that by 2009 the morbidity rates performance both for the working age population and older age people tended to increase, and from 2010 began to decline. Thus, among the working age population as a whole morbidity decreased from 63760.2 in 2009 to 59711.2 in 2012 per 100 thousand of population. There is an increase of morbidity in older age population - 52099.6 per 100 thousand population in 2009 and then gradual decline - 49734.0 per 100 thousand population in 2012 (Fig. 1).

The evolution of all diseases' prevalence in the population of working age has undulating nature. Thus, in 2 years dynamics for (2008-2010) the prevalence increased, but since 2010 the number of sick people began to decline. The opposite trend was observed in older age population, in particular, there is a negative trend of increasing prevalence - from 27 5334.0 in 2008 up to 3266.828 in 2012 per 100 thousand of population (Fig. 2).

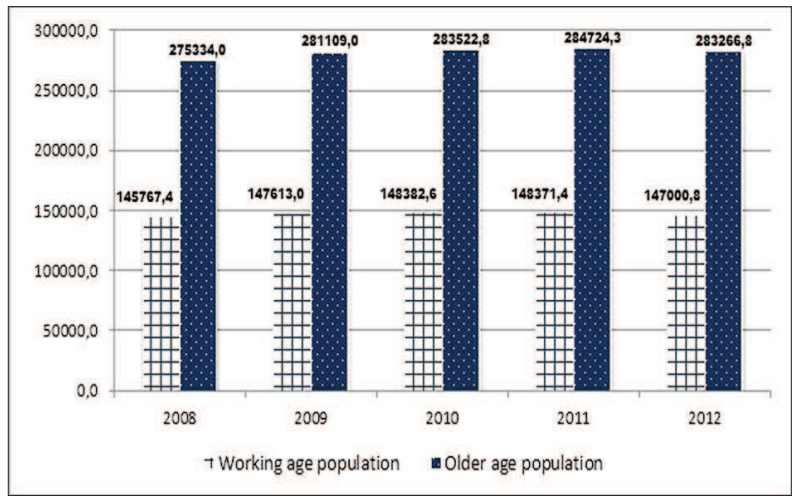

Fig. 2. All diseases' prevalence dynamics in the working and older age population in 2008-2012 (per 100 thousand of population) 
The revealed differences between morbidity and prevalence in the working and older age population indicate certain disease "accumulation" with simultaneous increase in life expectancy. This trend of general morbidity shows that there are "favorable" factors - improvement of the quality of patient's life, including the quality of medical care.

Taking into account the significant increase in the prevalence of pathological state among elderly, the next stage of our study was to analyze the epidemiological indicators of the population of this age.

On the basis of the data given by the Centre for Medical Statistics of the Health Care Ministry of Ukraine we found, over the period of 2008-2012, a positive trend towards gradual reduction of morbidity in general and by the its basic structure classes, except for eye diseases and its appendage. Particularly, all diseases rates decreased by $2.91 \%$ compared to 2008 and by $2.51 \%$ - since 2011 . Regarding the major structure classes, the most significant changes take place among the registered respiratory diseases - the morbidity of which decreased from

12368.6 in 2008 to 11549.9 in 2012 per 100 thousand population by $6.62 \%$, diseases of the circulatory system - by $6,59 \%$, diseases of the muscular system and connective tissue - by $4,91 \%$.

However, compared to 2008, morbidity rates of the eye and its appendage increased by $0.46 \%$, and injuries, poisoning and other consequences of external factors increased by $0.55 \%$ compared to 2011 (Fig.3).

It should be noted that all diseases' prevalence in elderly population for the period of 2008-2011 had a steady upward trend, only in 2012, there was a slight decrease (by $0.51 \%$ compared to the previous year).

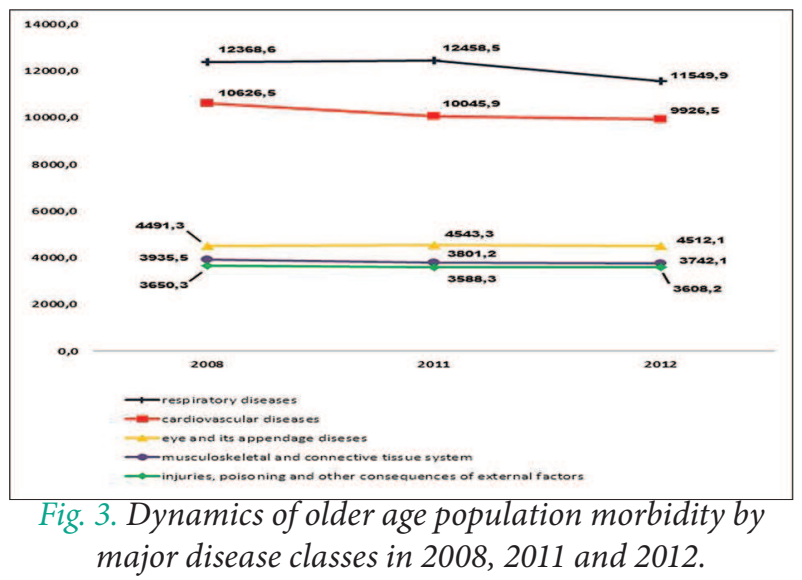

In the major disease classes over the past five years (2008-2012) the morbidity grew, except for respiratory diseases, which had a positive downward trend. Thus, digestive system diseases increased by 6.17 , diseases of the circulatory system - by $2.15 \%$, diseases of the eye and its appendage - by $0,98 \%$, musculoskeletal and connective tissue system diseases - by $0.44 \%$.

However, the positive trend in 2012 had a slight decline in all disease classes. It should also be noted that the class of respiratory diseases tended to decrease - from 22,534.6 in 2008 to 21,824.7 in 2012 per 100 thousand people (3.15\%) (Fig. 4).

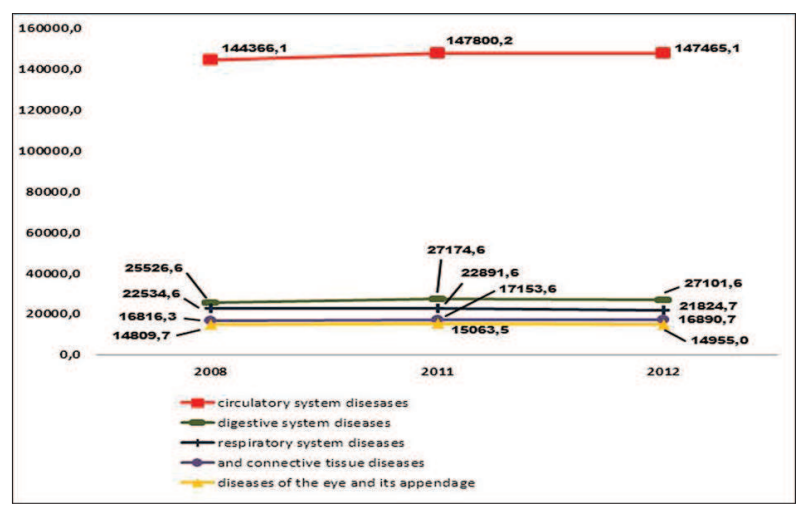

Fig. 4. Dynamics of the major disease classes' prevalence in older age population in 2008, 2011 and 2012.

Thus, despite the revealed positive trend of reduced general morbidity by most major classes diseases in 2012, compared to 2008 and 2011, the disease prevalence had yet a clear dynamics of growth. However, it should be noted that in 2011 there was a slight decrease in the mentioned rates, which gives hope to stabilize the health of elderly people. The received information indicates the features of older age population health level which requires additional attention when developing healthcare programs for elderly people at a national level.

\section{CONCLUSIONS}

According to the results of the analysis we found that for the period of 2008-2012 the morbidity among the older age was lower than those of working age, on the average by $17.9 \%$ and the prevalence was higher by $47.6 \%$, which indicates that chronic diseases have a significant advantage in elderly population. 
Also, the results indicate that the morbidity among the major diseases classes in older age population of Ukraine has a positive downward trend. The most significant changes take place among the registered respiratory diseases - morbidity decreased by $6.62 \%$, diseases of the circulatory system - by $6.59 \%$, diseases of the musculoskeletal system and connective tissue - by $4.91 \%$.

There is an alarming increase in the morbidity of the eye diseases and its appendage - by $0.46 \%$ compared to 2008, and injuries, poisoning and certain other consequences of external factors increased by $0.55 \%$ compared to 2011 .

As for general morbidity, it was found that in the period of 2008-2011, these indicators had a negative tendency to increase, but since 2012, there has been a slight decrease of them. It should be noted that there was a positive exception of respiratory diseases, prevalence rates of which decreased by $3.15 \%$ compared to 2008.

Taking into account these trends of morbidity and diseases prevalence among the older age population of Ukraine, the main directions of health improvement of the noted category, in our opinion, are:

* introduction of modern methods of diagnosis and improvement of the material and technical base of medical institutions;

* provision of access to and quality of health care;

* holding an annual pensioners medical examination in clinics;

* training of doctors and junior specialists in gerontology and geriatrics;

* improvement of the normative legal basis for the health protection of the elderly;

* unconditional implementation of existing legislation on granting guaranteed health care and adequate pharmaceutical provision to the older age group population;

* proper functioning of medical institutions by ensuring the coordination of their activities and quarterly reporting obligations;

* implementation of measures aimed at promoting healthy lifestyles;

* raising the population educational level on disease prevention, particularly in elderly and senile age.

\section{REFERENCES}

1. Kotvitska AA, Pastukhova OA. The problem of populations ageing in Ukraine and Russia. Statement of BelSU. 2013;11(154):5-9. Russian.

2. Parkhomenko GY, Kurchatov GV, Avramenko OI, Bidnuj VV. Analytical assessment of health status in older age population. Ukrainian. Health of the Nation. 2011;3(19). Ukranian.

3. Lifaryeva NV. Old age as a social problem. Journal of Luhansk National Taras Shevchenko University. 2012;4(239):260-266. Ukrainian.

4. Chaikovska VV, Stadnyuk LA. Ukraine ageing society: needs and solutions. Problems of ageing and longevity. 2011;20(2):57-63. Ukrainian.

5. Annual report on the state of health of Ukraine and sanitary epidemiological situation in 2008. In Bogatyryova RV. Kyiv: Ministry of Health of Ukraine; 2009. 360 p. Ukrainian.

6. Annual report on the state of health of Ukraine and sanitary epidemiological situation in 2012. In

Bogatyryova RV. editor. Kyiv: Ministry of Health of Ukraine; 2013. 464 p. Ukrainian.

7. Tarantino L, Chankova S, Pribl E, et al. Analysis of Health of Ukraine, MD: Project Health Systems 20/20, Abt Associates Inc. Abt.; 2011. 179 p. Ukrainian. 